\title{
Development of a simple, low-cost and eurytopic medium based on Pleurotus eryngii for lactic acid bacteria
}

\author{
Yancun Zhao ${ }^{1}$, Ying Wang ${ }^{2}$, Zhiwei Song ${ }^{1}$, Chengjun Shan², Runjie Zhu ${ }^{1}$ and Fengquan Liu ${ }^{*}$
}

\begin{abstract}
Lactic acid bacteria $(\mathrm{LAB})$ are a group of important beneficial microorganisms for human, but their growth is restricted to the habitats with rich nutrients. In order to develop a simple, low-cost and efficient medium based on the mushroom Pleurotus eryngii, this study evaluated the effects of different treatment methods for the mushroom, concentration of the mushroom, buffers, tween $80, \mathrm{MgSO}_{4} \cdot 7 \mathrm{H}_{2} \mathrm{O}, \mathrm{MnSO}_{4} \cdot 4 \mathrm{H}_{2} \mathrm{O}, \mathrm{CuSO}_{4} \cdot 5 \mathrm{H}_{2} \mathrm{O}$, riboflavin and ascorbic acid on the growth of Lactococcus lactis subsp. lactis SLPE1-3. An optimized medium was developed, which was composed of the mushroom at $200 \mathrm{~g} / \mathrm{L}$, the buffer sodium acetate at $5 \mathrm{~g} / \mathrm{L}$, and riboflavin at $0.5 \mathrm{mg} / \mathrm{L}$. The mushroom was ground, boiled and filtered for the filtrate in advance. In this optimized medium which was named as PSR medium, the population density of SLPE1-3 sharply reached $2.13 \times 10^{9} \mathrm{CFU} / \mathrm{mL}$ within $18 \mathrm{~h}$ of incubation, and still maintained $1.17 \times 10^{8} \mathrm{CFU} / \mathrm{mL}$ at $120 \mathrm{~h}$. In addition, this study found that 6 kinds of $L A B$ could grow almost well, and maintained high survival in PSR medium compared to M17 or MRS medium, including Lactococcus lactis subsp. lactis, Lactobacillus plantarum, Lactococcus lactis subsp. cremoris, Lactobacillus paracasei, Pediococcus pentosaceus and Lactobacillus rhamnosus. These results showed that PSR medium was a simple, low cost and eurytopic medium for the cultivation of $L A B$, and could replace MRS or M17 medium in the food industry, biomedicine and laboratory.
\end{abstract}

Keywords: Lactic acid bacteria, Pleurotus eryngii, Nutrient requirements, Sodium acetate, Riboflavin

\section{Introduction}

Lactic acid bacteria (LAB) are a diverse group of Grampositive, nonsporulating, low $\mathrm{G}+\mathrm{C}$ content bacteria that include cocci and bacilli, such as Lactococcus, Lactobacillus, Streptococcus, Pediococcus and Leuconostoc (D'Souza et al. 2012; Wyszyńska et al. 2015). Many bacteria of this group are long known as starters of dairy, plant, and meat fermentations, and could improve the taste and texture of the fermented foods (Price et al. 2012). Thus they are usually retained as beneficial microorganisms for human and animal (Wyszyńska et al. 2015). But it is worthwhile to mention that some strains of LAB could also cause serious diseases in neonates, aquatic animals and

\footnotetext{
*Correspondence: fqliu20011@sina.com

1 Institute of Plant Protection, Jiangsu Academy of Agricultural Sciences, Nanjing 210014, China

Full list of author information is available at the end of the article
}

postharvest mushroom (Wang et al. 2008; Daniel et al. 2011; Zhao et al. 2013).

During the last two decades, LAB are extensively studied and used in food technology and biomedicine because of their commercial potential, especially Lactococcus lactis and some species of the Lactobacillus genus (Aller et al. 2014; Wyszyńska et al. 2015). But these microorganisms are fastidious in nutrient requirements, and their growth is restricted to the habitats with rich nutrients (van Niel and Hahn-Hägerdal 1999; Price et al. 2012). During the long process of evolution, LAB lost a number of genes for the biosynthesis of cofactors, and lack various biosynthetic pathways for important nutrients, especially amino acids and vitamins (van Niel and Hahn-Hägerdal 1999; Kelly et al. 2010). Therefore, most of $L A B$ required rich nutrients for their well growth. It is very difficult to develop a generally applicable defined medium for these organisms. Currently, the rich and undefined media are extensively used for culturing LAB, 
such as MRS medium (De Man et al. 1960) and M17 broth (Terzaghi and Sandine 1975). But these media are composed of diversiform materials, and their prices are very high, such as yeast extract, peptone, polypeptone, soy peptone, beef extract.

Pleurotus eryngii is a kind of favored oyster mushroom, and contains rich nutrients, such as protein, fiber, carbohydrates, vitamins and minerals (Cohen et al. 2002; $\mathrm{Li}$ and Shah 2015). Li and Shah (2015) found that polysaccharide extracted from $P$. eryngii could promote the proliferation of Streptococcus thermophilus in fermented milk, and enhance its viability rate during refrigerated storage at $4{ }^{\circ} \mathrm{C}$ (Li and Shah 2015). In the previous study, we found that $L$. lactis subsp. lactis could quickly proliferate on the surface of post-harvest $P$. eryngii, and cause water-soaked lesions (Zhao et al. 2013).

Currently, P. eryngii has been extensively cultivated in the world (Zhao et al. 2013; Li and Shah 2015). During the cultivation, there is plentiful low-cost inferior mushroom. The objective of this research was to develop a low-cost, simple and eurytopic medium based on the inferior $P$. eryngii, which could replace MRS or M17 broth medium for cultivating various LAB.

\section{Materials and methods}

\section{Bacterial strains and growth conditions}

All bacterial strains used in this study and their origin are listed in Table 1. Six strains of them were isolated from different habitats by our laboratory, including $L$. lactis subsp. lactis SLPE1-3, Lactobacillus plantarum P13, Streptococcus thermophilus M1-6, Lactobacillus paracasei FM-LP-4, Leuconostoc mesenteroides JX5 and Pediococcus pentosaceus SR2-6. L. lactis subsp. cremoris MG1363 was donated by Prof. Lixin Luo (South China University of Technology, China). Lactobacillus rhamnosus GG was purchased from American Type Culture Collection (ATCC, America). Unless otherwise stated, all bacterial strains were grown at $30{ }^{\circ} \mathrm{C}$ for $18 \mathrm{~h}$ in MRS medium (proteose peptone at $10 \mathrm{~g} / \mathrm{L}$, beef extract at
$10 \mathrm{~g} / \mathrm{L}$, yeast extract $5 \mathrm{~g} / \mathrm{L}$, dextrose $20 \mathrm{~g} / \mathrm{L}$, polysorbate $801 \mathrm{~mL} / \mathrm{L}$, ammonium citrate $2 \mathrm{~g} / \mathrm{L}$, sodium acetate $5 \mathrm{~g} / \mathrm{L}$, magnesium sulfate $0.1 \mathrm{~g} / \mathrm{L}$, manganese sulfate $0.05 \mathrm{~g} / \mathrm{L}$, dipotassium phosphate $2 \mathrm{~g} / \mathrm{L}, \mathrm{pH}$ 6.8). The bacterial culture was used as inoculum in the following experiments.

\section{Effect of different treatment methods for $P$. eryngii on the growth of L. lactis subsp. lactis}

In this study, the fresh mushroom P. eryngii was bought from a super vegetable wholesale market in Nanjing, Jiangsu Province, China. The mushroom was cut into small pieces $\left(1.5-2.0 \mathrm{~cm}^{3}\right)$ for this experiment. This experiment included three treatments: (1) $200 \mathrm{~g}$ of the mushroom was ground in a blender (MJ-M176P, Panasonic Limited, Malaysia) for $3 \mathrm{~min}$ at high speed with $400 \mathrm{~mL}$ water. The mushroom slurry was supplemented with $500 \mathrm{~mL}$ water, boiled for $20 \mathrm{~min}$, and then filtered through two layers of medical gauze. The final volume of the filtrate was increased to $1000 \mathrm{~mL}$ by supplemented water; (2) $200 \mathrm{~g}$ of the mushroom was ground according to the above description, and then filtered through two layers of medical gauze. The final volume of the filtrate was increased to $1000 \mathrm{~mL}$ by supplemented water; (3) $200 \mathrm{~g}$ of the mushroom were boiled for $20 \mathrm{~min}$, and then filtered through two layers of medical gauze. The final volume of the filtrate was increased to $1000 \mathrm{~mL}$ by supplemented water. The $\mathrm{pH}$ values were adjusted to $6.8 \pm 0.1$, respectively. These media were sterilized for 20 min at $121^{\circ} \mathrm{C}$.

Subsequently, $250 \mu \mathrm{L}$ of $L$. lactis subsp. Lactis SLPE1-3 culture was added to $50 \mathrm{~mL}$ of the above-mentioned filtrate media respectively, and incubated for $72 \mathrm{~h}$ at $30{ }^{\circ} \mathrm{C}$ without shaking. The population dynamics of SLPE1-3 was investigated after $0,3,9,18,30,48$ and $72 \mathrm{~h}$ of incubation by the gradient dilution method. In brief, each bacterial culture was diluted with sterile water, and the diluents were plated on MRS agar plates respectively. The number of bacterial colonies on each plate was counted

Table 1 Lactic acid bacteria (LAB) strains used in this study

\begin{tabular}{|c|c|c|}
\hline Strain & Origin & Source or reference \\
\hline Lactococcus lactis subsp. lactis SLPE1-3 (CGMCC12634) & Pleurotus eryngii & This laboratory \\
\hline Lactobacillus plantarum P13 & Fermented vegetables & This laboratory \\
\hline Lactococcus lactis subsp. cremoris MG1363 & Plasma cured strain NCDO 712 & Jensen and Hammer (1993) \\
\hline Streptococcus thermophilus M1-6 & Dairy & This laboratory \\
\hline Lactobacillus paracasei FM-LP-4 (CGMCC8600) & Dairy & This laboratory \\
\hline Pediococcus pentosaceus SR2-6 & Sour meat & This laboratory \\
\hline Lactobacillus rhamnosus GG (ATCC53103) & Human gastrointestinal tract & Gorbach (1996) \\
\hline Leuconostoc mesenteroides JX5 & Kefir & This laboratory \\
\hline
\end{tabular}


after incubating for $24 \mathrm{~h}$ at $30{ }^{\circ} \mathrm{C}$. Every treatment included three repetitions.

\section{Effect of different concentration of $P$. eryngii on the growth of $L$. lactis subsp. lactis}

According to the description in the above section, 100, 150, 200 and $250 \mathrm{~g}$ of the mushroom was respectively ground to make mushroom slurry, boiled for $20 \mathrm{~min}$, and then filtered. The final volume of each filtrate was increased to $1000 \mathrm{~mL}$ by supplemented water. The $\mathrm{pH}$ values were initially adjusted to $6.8 \pm 0.1$, respectively. These media were sterilized for $20 \mathrm{~min}$ at $121^{\circ} \mathrm{C}$. Subsequently, $250 \mu \mathrm{L}$ of L. lactis subsp. lactis SLPE1-3 culture was added to $50 \mathrm{~mL}$ of the filtrate media respectively, and incubated for $72 \mathrm{~h}$ at $30{ }^{\circ} \mathrm{C}$ without shaking. The population dynamics of SLPE1-3 was investigated after 0, 9, $18,30,48$ and $72 \mathrm{~h}$ of incubation by the gradient dilution method. Every treatment included three repetitions.

\section{Effect of different buffers on the growth of L. lactis subsp. lactis}

According to the description in the above section, $1000 \mathrm{~g}$ of the mushroom was ground to make mushroom slurry, boiled for $20 \mathrm{~min}$, and then filtered. The filtrate was equally divided into five parts. Three kinds of buffers, including to ammonium citrate, sodium acetate and dipotassium phosphate, were selected and supplemented based on MRS medium (De Man et al. 1960). This experiment included five treatments: (1) the filtrate was supplemented with ammonium citrate at a final concentration of $2 \mathrm{~g} / \mathrm{L}$; (2) the filtrate was supplemented with sodium acetate at a final concentration of $5 \mathrm{~g} / \mathrm{L}$; (3) the filtrate was supplemented with dipotassium phosphate at a final concentration of $2 \mathrm{~g} / \mathrm{L}$; (4) the filtrate was supplemented with ammonium citrate at $2 \mathrm{~g} / \mathrm{L}$, sodium acetate at $5 \mathrm{~g} / \mathrm{L}$, and dipotassium phosphate at $2 \mathrm{~g} / \mathrm{L}$; (5) the filtrate without buffer was as the control. The final volume of each filtrate was increased to $1000 \mathrm{~mL}$ by supplemented water. The $\mathrm{pH}$ values were initially adjusted to $6.8 \pm 0.1$, respectively. These media were sterilized for $20 \mathrm{~min}$ at $121^{\circ} \mathrm{C}$.

Subsequently, $250 \mu \mathrm{L}$ of $L$. lactis subsp. lactis SLPE1-3 culture was added to $50 \mathrm{~mL}$ of the above-mentioned filtrate media, respectively, and incubated for $72 \mathrm{~h}$ at $30^{\circ} \mathrm{C}$ without shaking. The population dynamics of SLPE1-3 was investigated after $0,9,18,30,48$ and $72 \mathrm{~h}$ of incubation by the gradient dilution method. Every treatment included three repetitions.

\section{Effect of different additives on the growth of $L$. lactis subsp. lactis}

In this experiment, $200 \mathrm{~g}$ of the mushroom was ground to make mushroom slurry, boiled for $20 \mathrm{~min}$, and then filtered. The filtrate was supplemented with sodium acetate at a final concentration of $5 \mathrm{~g} / \mathrm{L}$. The final volume of the filtrate was increased to $1000 \mathrm{~mL}$ by supplemented water. The seven kinds of additives were added respectively to the filtrate at the following final concentrations: glucose $5 \mathrm{~g} / \mathrm{L}$, tween $800.5 \mathrm{ml} / \mathrm{L}, \mathrm{MgSO}_{4} \cdot 7 \mathrm{H}_{2} \mathrm{O} 0.2 \mathrm{~g} / \mathrm{L}$, $\mathrm{MnSO}_{4} \cdot 4 \mathrm{H}_{2} \mathrm{O} 20 \mathrm{mg} / \mathrm{L}, \mathrm{CuSO}_{4} \cdot 5 \mathrm{H}_{2} \mathrm{O} 3 \mathrm{mg} / \mathrm{L}$, riboflavin $0.5 \mathrm{mg} / \mathrm{L}$, ascorbic acid $0.5 \mathrm{mg} / \mathrm{L}$. These additives were selected based on their previously reported influences on the growth of L. lactis (De Man et al. 1960; van Niel and Hahn-Hägerdal 1999; Aller et al. 2014). The filtrate without additive was as the control. The $\mathrm{pH}$ values were initially adjusted to $6.8 \pm 0.1$, respectively. These media were sterilized for $20 \mathrm{~min}$ at $121^{\circ} \mathrm{C}$.

Subsequently, $250 \mu \mathrm{L}$ of $L$. lactis subsp. lactis SLPE1-3 culture was added to $50 \mathrm{~mL}$ of the above-mentioned filtrate media, respectively, and incubated for $120 \mathrm{~h}$ at $30{ }^{\circ} \mathrm{C}$ without shaking. The population dynamics of SLPE1-3 was investigated after $0,9,18,30,48,72$ and $120 \mathrm{~h}$ of incubation by the gradient dilution method. Every treatment included three repetitions.

\section{Growth dynamics of eight LAB strains in PSR, MRS and M17 media}

Based on the above experimental results, the optimized medium was composed of the mushroom filtrate at $200 \mathrm{~g} / \mathrm{L}$, sodium acetate at $5 \mathrm{~g} / \mathrm{L}$, and riboflavin at $0.5 \mathrm{mg} / \mathrm{L}$. This medium was named as PSR medium. The $\mathrm{pH}$ value was adjusted to $6.8 \pm 0.1$. Then the medium was sterilized for $20 \mathrm{~min}$ at $121^{\circ} \mathrm{C}$.

Subsequently, $250 \mu \mathrm{L}$ of each $\mathrm{LAB}$ strain culture was added to $50 \mathrm{~mL}$ of PSR, MRS or M17 medium (Hope Bio-Technogy, Qingdao, China) respectively, and incubated for $120 \mathrm{~h}$ at $30{ }^{\circ} \mathrm{C}$ without shaking. The population dynamics of each LAB strain was investigated after 0 , $3,9,18,30,48,72$ and $120 \mathrm{~h}$ of incubation by the gradient dilution method. Every treatment included three repetitions.

\section{Statistical analysis}

Every treatment was randomly arranged with three replicates. All data obtained were subjected to analysis of variance (ANOVA) using SPSS 13.0 software (SPP Inc., Chicago, USA). The mean values were compared using Tukey's test at $P<0.05$.

\section{Results}

Effect of different treatment methods for $P$. eryngii on the growth of $L$. lactis susp. lactis

In three different treatments for $P$. eryngii, the growth of L. lactis susp. lactis SLPE1-3 showed a similar trend (Fig. 1). The cell density increased sharply within $9 \mathrm{~h}$ of incubation, kept a high level from 9 to $30 \mathrm{~h}$ of incubation, and then decreased rapidly after 30 of inoculation. But 


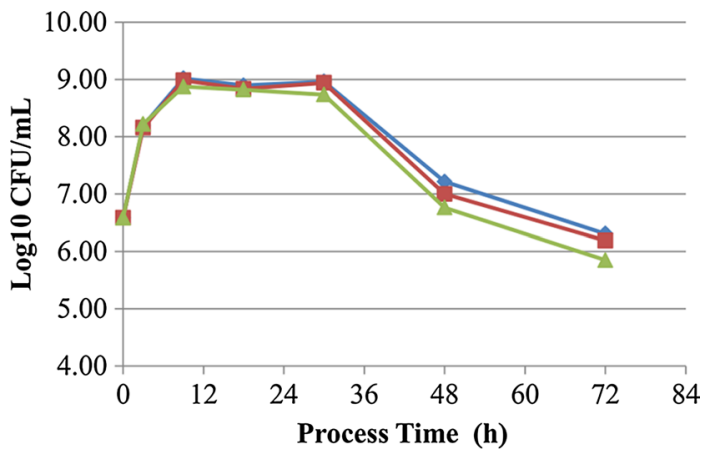

Fig. 1 Effect of different treatment methods for Pleurotus eryngii mushroom on the growth of Lactococcus lactis subsp. lactis SLPE1-3. Filled diamond the mushroom was ground in a blender for $3 \mathrm{~min}$, boiled for $20 \mathrm{~min}$, and then filtered; filled square the mushroom was ground in a blender for $3 \mathrm{~min}$, and then filtered; filled triangle the mushroom was boiled for $20 \mathrm{~min}$, and then filtered. Each symbol is the average of three replicates

\section{Effect of different buffers on the growth of $L$. lactis subsp.} lactis

MRS medium, which was extensively used for culturing various $\mathrm{LAB}$ species, contained three kinds of buffers, including ammonium citrate, sodium acetate and dipotassium phosphate. When these buffers were supplemented alone or jointly to the $P$. eryngii medium, the population density of L. lactis susp. lactis SLPE1-3 was significantly higher than that of the control without any buffer, especially alone sodium acetate at the late stage of incubation (Fig. 3a). At $72 \mathrm{~h}$ of incubation, the viable count in the medium supplemented with sodium acetate $(5 \mathrm{~g} / \mathrm{L})$ was $9.67 \times 10^{8} \mathrm{CFU} / \mathrm{mL}$, which was 403.9 times that of the control. In addition, alone sodium acetate or the jointly buffers showed higher buffer capacity than ammonium citrate and dipotassium phosphate (Fig. 3b). Hence, sodium acetate was used as the buffer in the following experiments. the mushroom P. eryngii medium, which was ground and boiled, could improve survival probability compared to other treatment methods at the late stage of incubation. Hence, the mushroom P. eryngii was ground, boiled and filtered for the subsequent experiments.

\section{Effect of different concentration of $P$. eryngii on the growth of $L$. lactis subsp. lactis}

In this experiment, there was a positive relationship between the cell density of L. lactis subsp. lactis SLPE1-3 and the concentration of $P$. eryngii $(<200 \mathrm{~g} / \mathrm{L})$, especially at the late stage (Fig. 2). But there was not remarkably difference between 200 and $250 \mathrm{~g} / \mathrm{L}$ of $P$. eryngii. Hence, $1000 \mathrm{~mL}$ medium contained $200 \mathrm{~g}$ of the mushroom $P$. eryngii in the following experiments.

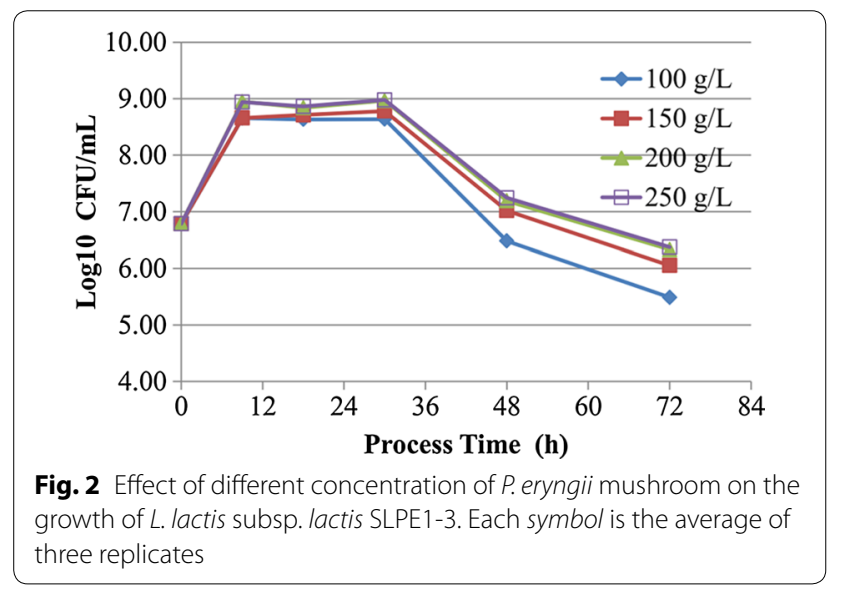

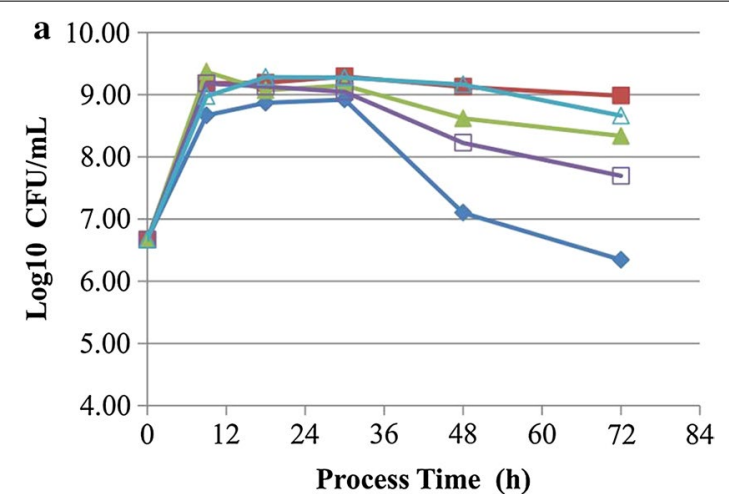

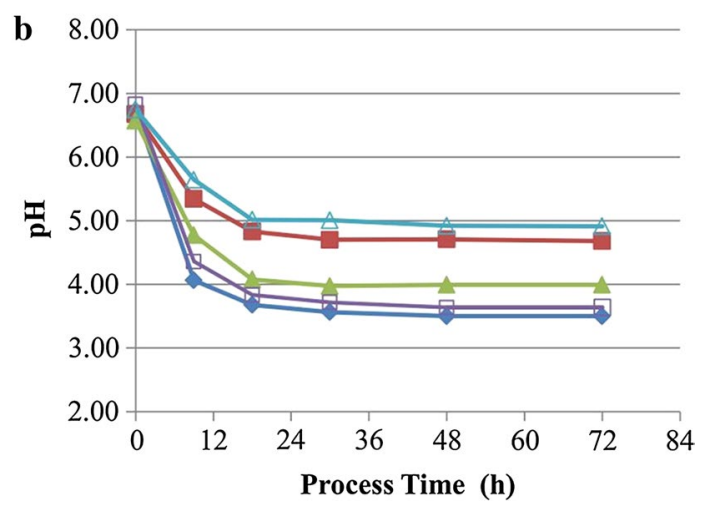

Fig. 3 Effect of different buffers on the growth of L. lactis subsp. lactis SLPE1-3 (a) and the pH values of the culture media (b). Filled diamond the control without buffer; filled square sodium acetate at $5 \mathrm{~g} / \mathrm{L}$; filled triangle ammonium citrate at $2 \mathrm{~g} / \mathrm{L}$; open square dipotassium phosphate at $2 \mathrm{~g} / \mathrm{L}$; open triangle sodium acetate at $5 \mathrm{~g} / \mathrm{L}$, ammonium citrate at $2 \mathrm{~g} / \mathrm{L}$ and dipotassium phosphate at $2 \mathrm{~g} / \mathrm{L}$. Each symbol is the average of three replicates 
Effect of different additives on the growth of L. lactis subsp. lactis

In this experiment, we investigated the effect of seven additives on the growth of L. lactis subsp. lactis SLPE13 . The results showed that these additives could not promote the growth of SLPE1-3 within $72 \mathrm{~h}$ after inoculating compared to the control without additives (Fig. 4a). After $48 \mathrm{~h}$ of incubation, the population densities of SLPE1-3 sharply decreased in the media supplemented difference additives, especially glucose, $\mathrm{MnSO}_{4}$ and $\mathrm{CuSO}_{4}$ (Fig. 4a). But the additives tween 80 , riboflavin and ascorbic acid could remarkably delay the contabescence of SLPE1-3 compared to the control, especially riboflavin. At $120 \mathrm{~h}$ of incubation, the population density of SLPE1-3 in the medium supplemented riboflavin was 8.88 times that of the control. In addition, the additive glucose prevented the growth of SLPE1-3 at the earlier stage compared to the control, and promoted its contabescence at the later stage. Among seven additives, only glucose significantly promoted the decrease in the $\mathrm{pH}$ value of the culture medium compared to the control (Fig. 4b). The lower $\mathrm{pH}$
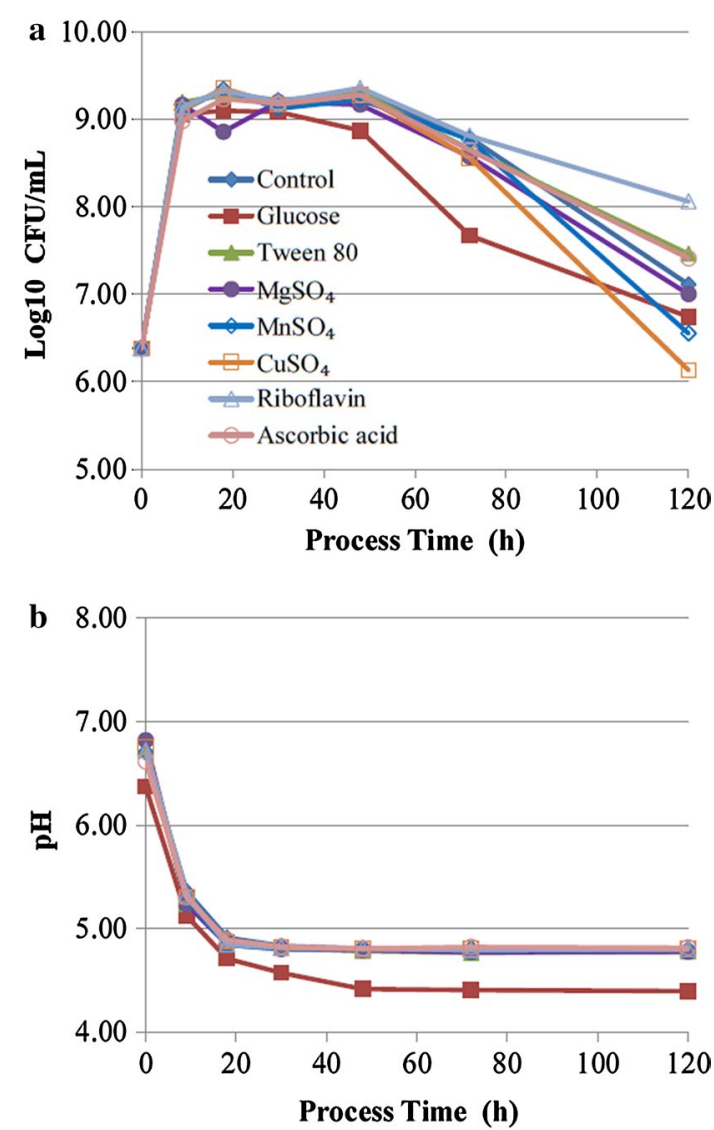

Fig. 4 Effects of 7 kinds of additives on the growth of L. lactis subsp. lactis (a) and the $\mathrm{pH}$ values of the culture media (b). Each symbol is the average of three replicates value might be disadvantageous to the growth and viability of LAB.

Based on these results, the optimized medium was composed of the mushroom P. eryngii at $200 \mathrm{~g} / \mathrm{L}$, sodium acetate at $5 \mathrm{~g} / \mathrm{L}$, and riboflavin at $0.5 \mathrm{mg} / \mathrm{L}$, which was named as PSR medium. In addition, the physical property of PSR medium was relatively stable, and there was not obvious sedimentation and layer phenomena within 30 days of storage at room temperature (Fig. 5).

\section{Growth dynamics of eight LAB strains in PSR, MRS and M17 media}

To examine the suitability of PSR medium for various $\mathrm{LAB}$, a total of $8 \mathrm{LAB}$ strains, belonging to seven species, were tested for their growth in PSR, MRS and M17 media. Three strains of them (L. lactis subsp. lactis SLPE1-3, L. plantarum P13, L. lactis subsp. cremoris MG1363) grew almost as well and remained highly survival rates in PSR and M17 media, but their population densities were sharply decreased after $48 \mathrm{~h}$ of incubation in MRS medium (Fig. 6a-c). Two strains of them (L. paracasei FM-LP-4, Pediococcus pentosaceus SR2-6) grew almost as well in PSR and MRS medium, and better compared to M17 medium (Fig. 6e, f). One strain of them (Lactobacillus rhamnosus GG) grew better in PSR

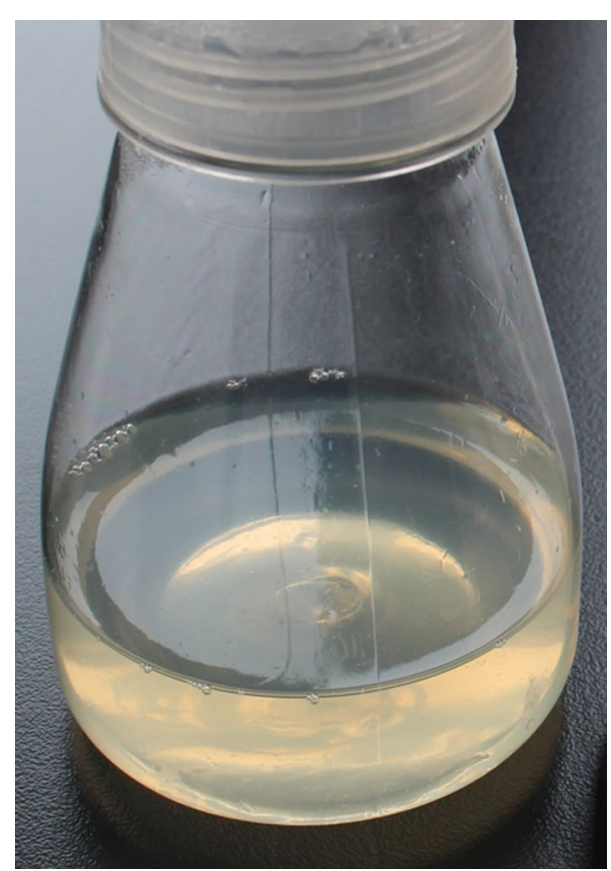

Fig. 5 Physical form of the liquid PSR medium which was composed of Pleurotus eryngii mushroom at $200 \mathrm{~g} / \mathrm{L}$, sodium acetate at $5 \mathrm{~g} / \mathrm{L}$, and riboflavin at $0.5 \mathrm{mg} / \mathrm{L}$. The mushroom was ground to make mushroom slurry, boiled for $20 \mathrm{~min}$, and then filtered for the filtrate in advance 

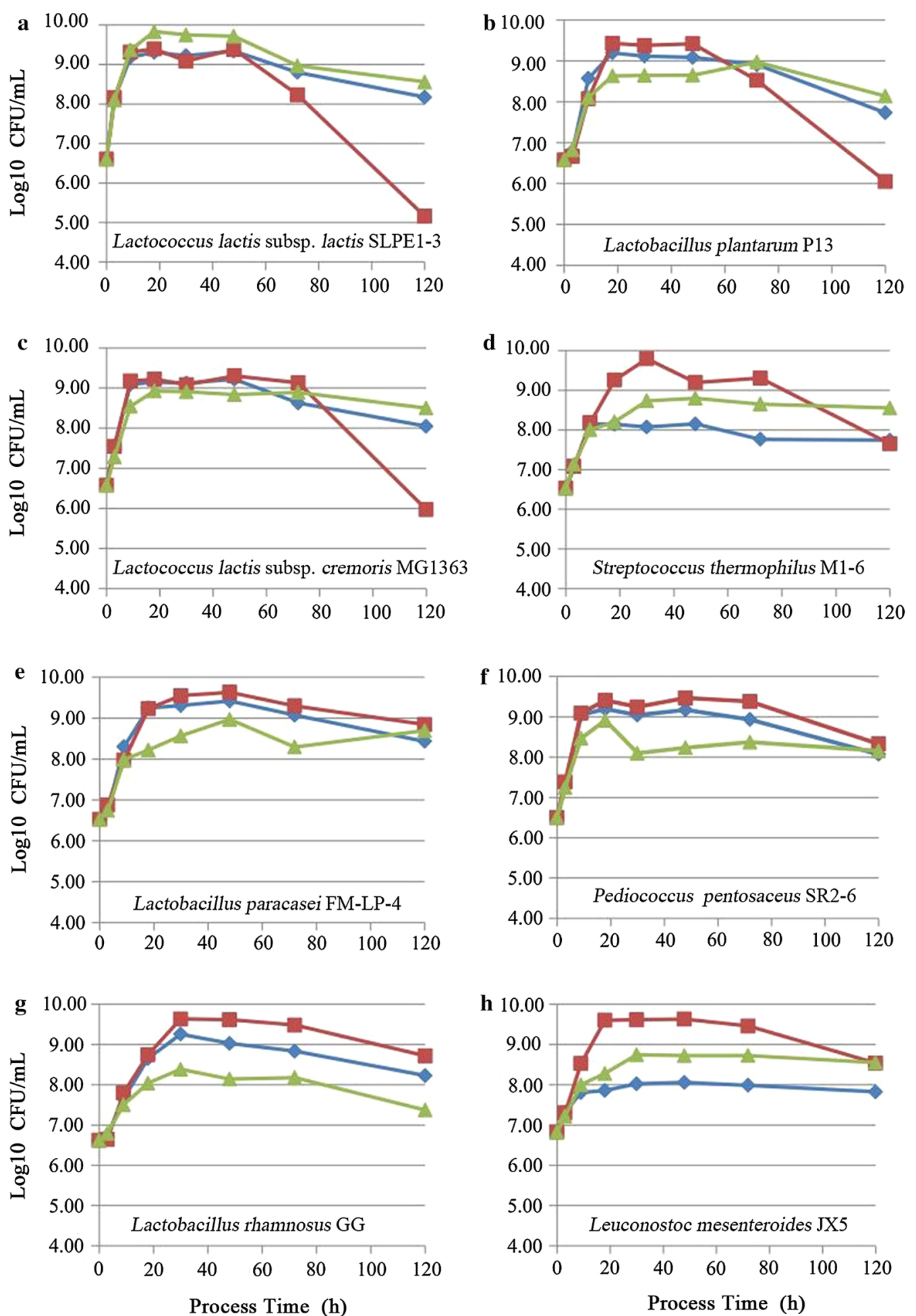

Fig. 6 Growth dynamics of eight lactic acid bacteria strains in PSR, MRS and M17 media. a Lactococcus lactis subsp. lactis SLPE1-3; b Lactobacillus plantarum P13; c Lactococcus lactis subsp. cremoris MG1363; d Streptococcus thermophilus M1-6; e Lactobacillus paracasei FM-LP-4; f Pediococcus pentosaceus SR2-6; $\mathbf{g}$ Lactobacillus rhamnosus GG; $\mathbf{h}$ Leuconostoc mesenteroides JX5. Filled diamond PSR medium which was composed of P. eryngii mushroom at $200 \mathrm{~g} / \mathrm{L}$, sodium acetate at $5 \mathrm{~g} / \mathrm{L}$, and riboflavin at $0.5 \mathrm{mg} / \mathrm{L}$; filled square MRS medium; filled triangle M17 medium. Each symbol is the average of three replicates 
medium compared to M17 medium, but poorly compared to MRS medium (Fig. $6 \mathrm{~g}$ ). In addition, two strains of them (S. thermophilus M1-6, L. mesenteroides JX5) grew poorly in PSR compared to MRS and M17 media (Fig. 6d, h). These results showed that PSR medium had high suitability for the cultivation of many LAB.

\section{Discussion}

The previous studies had demonstrated that 6-8 kinds of amino acids must be supplemented in chemically defined media (CDM) for the cultivation of various LAB (Jensen and Hammer 1993; Cocaign-Bousquet et al. 1995; Aller et al. 2014). Among these amino acids, glutamic acid and asparagine were the most important media components for the growth of many LAB (Aller et al. 2014). In addition, LAB could grow better in the medium containing 18-19 kinds of amino acids (van Niel and Hahn-Hägerdal 1999). The mushroom P. eryngii contains rich protein and free amino acids, especially aspartic acid, glutamic acid and arginine (Stajić et al. 2009). This study founded that 6 kinds of LAB could grow very well in PSR medium when the mushroom $P$. eryngii was used as only nitrogen source, and their population densities were more than $1 \times 10^{9} \mathrm{CFU} / \mathrm{mL}$ at $30 \mathrm{~h}$ of incubation. This study demonstrated that the mushroom $P$. eryngii could supply enough amino acids for the growth of most species of LAB.

In bioprocesses, the $\mathrm{pH}$ value is an important environmental factor. The influence of $\mathrm{pH}$ on the growth and metabolic processes of LAB had been extensively studied (van Niel and Hahn-Hägerdal 1999; Aller et al. 2014). The optimum $\mathrm{pH}$ for the growth of LAB was usual between 6.0 and 6.5. But, LAB produced much lactic acid during fermentation, which led to a sharp drop of the $\mathrm{pH}$ of the culture medium (Wyszyńska et al. 2015). The growth of $\mathrm{LAB}$ was inhibited when the $\mathrm{pH}$ of the culture medium was under 5.5 (van Niel and Hahn-Hägerdal 1999). The previous study had demonstrated that some buffers could improve the growth and viability of LAB, such as sodium acetate, ammonium citrate, dipotassium phosphate (De Man et al. 1960; Aller et al. 2014). In this study, we found that sodium acetate was a more suitable buffer for the growth and viability of L. lactis susp. lactis SLPE1-3 than ammonium citrate and dipotassium phosphate. Sodium acetate showed higher buffering ability for the $\mathrm{pH}$ of the culture medium than ammonium citrate and dipotassium phosphate. This study demonstrated again the lower $\mathrm{pH}$ of the culture medium remarkably prevented to the growth $\mathrm{LAB}$, and promoted the death of LAB (Broadbent et al. 2010).

Besides amino acids and $\mathrm{pH}$ value, many studies had demonstrated that several B-group vitamins were essential for the growth of LAB (van Niel and Hahn-Hägerdal
1999; Aller et al. 2014). Aller et al. (2014) founded that riboflavin (B2) was the only essential B-group vitamin for the growth of L. lactis IL1403 in the chemically defined media (CDM) experiment. Riboflavin is indispensable for cellular metabolism because it is the precursor of coenzymes flavin mononucleotide (FMN) and flavin adenie dinucleotide (FAD) (LeBlanc et al. 2011; Aller et al. 2014). The mushroom $P$. eryngii contains significant concentrations of vitamins, including $\mathrm{C}, \mathrm{A}, \mathrm{B}_{2}, \mathrm{~B}_{1}, \mathrm{D}$ and niacin (Manzi et al. 1999; Stajić et al. 2009). Hence, the PSR medium based on the mushroom P. eryngii contains rich vitamins. In this study, though the additive riboflavin could not further promote the growth of L. lactis susp. lactis SLPE1-3, it delayed the decay of SLPE1-3 in the culture medium compared to the control without the additive riboflavin.

Rich media MRS and M17 contain adequate amounts of minerals through the use of yeast extract, such as $\mathrm{Fe}^{2+}, \mathrm{Cu}^{2+}, \mathrm{Mg}^{2+}, \mathrm{Zn}^{2+}, \mathrm{Ca}^{2+}$, etc. (van Niel and HahnHägerdal 1999). Some studies founded that $\mathrm{Mg}^{2+}, \mathrm{Mn}^{2+}$ and $\mathrm{Cu}^{2+}$ could stimulate the growth of LAB (Olsen and Qutub 1970; Hansson and Häggström 1984; Loubiere et al. 1997; Aller et al. 2014). The mushroom P. eryngii contains rich mineral elements, especially $\mathrm{Mg}, \mathrm{Cu}, \mathrm{Mn}, \mathrm{K}$ and Ca (Stajić et al. 2009; Akyüz and Kirbag 2010). In this study, the supplementation of mineral elements $\left(\mathrm{MgSO}_{4}\right.$, $\mathrm{MnSO}_{4}$ and $\mathrm{CuSO}_{4}$ ) could not simulate the growth of $L$. lactis susp. lactis SLPE1-3. This result showed that the PSR medium based on the mushroom P. eryngii contained sufficient $\mathrm{Mg}, \mathrm{Mn}$ and $\mathrm{Cu}$, and excessive mineral elements were not conducive to the growth and viability of LAB.

Since LAB have been extensively used in food technology, biomedicine and scientific experiments, some researchers committed themselves to developing a simple and low-cost medium for the growth of various LAB (De Man et al. 1960; Terzaghi and Sandine 1975; Rodriguez et al. 2010; Aller et al. 2014). During the fermentation of L. lactis CECT-4434 for producing lactic acid and biosurfactant, MRS medium could be replaced with two waste materials: trimming vine shoots as $\mathrm{C}$ source, and distilled wine lees as N, P and micronutrient sources (Rodriguez et al. 2010). In this study, PSR medium was only composed of the low-cost mushroom P. eryngii, sodium acetate and riboflavin. The cost of raw materials is only 0.8 dollar or so for $1 \mathrm{~L}$ of PSR medium in China, but about 2.5 dollars for $1 \mathrm{~L}$ of MRS or M17 medium. PSR medium could replace MRS or M17 medium for the cultivation of L. lactis subsp. lactis, L. plantarum, L. lactis subsp. cremoris, L. paracasei, P. pentosaceus, L. rhamnosus, etc.

In conclusion, this study developed a kind of simple, low-cost and eurytopic medium (PSR medium). Compared to MRS or M17 medium, many LAB could grow 
almost as well, and remain highly survival rates in PSR medium. Hence, PSR medium could replace MRS or M17 medium for the cultivation of many LAB in the food industry, biomedicine and laboratory.

\section{Abbreviations}

LAB: lactic acid bacteria; CGMCC: China General Microbiological Culture Collection Center; ATCC: American Type Culture Collection; CDM: chemically defined media; FMN: flavin mononucleotide; FAD: flavin adenie dinucleotide; ANOVA: analysis of variance.

\section{Authors' contributions}

Planning and designing of study: FL, YZ; Experimentation: YZ, YW, RZ; Result Analysis:YZ, YW, CS; Manuscript Drafting: YZ, ZS, FL. All authors contributed in the final approval. All authors read and approved the final manuscript.

\section{Author details}

${ }^{1}$ Institute of Plant Protection, Jiangsu Academy of Agricultural Sciences, Nanjing 210014, China. ${ }^{2}$ Institute of Agro-product Processing, Jiangsu Academy of Agricultural Sciences, Nanjing 210014, China.

\section{Acknowledgements}

The authors are very grateful to Prof. Lixin Luo (South China University of Technology, China) for kindly providing Lactococcus lactis subsp. cremoris MG1363.

\section{Competing interests}

The authors declare that they have no competing interests.

\section{Ethics approval and consent to participate}

This article does not contain any studies concerned with experimentation on human or animals.

\section{Funding}

This study was funded by the National Natural Science Foundation of China (31471637)

Received: 22 July 2016 Accepted: 18 August 2016

Published online: 02 September 2016

\section{References}

Akyüz M, Kirbag S. Element contents of Pleurotus eryngii (DC. ex Fr.) Quel. Var eryngii grown on some various agro-wastes. Ekoloji. 2010;9(74):10-4.

Aller K, Adamberg K, Timarova V, Seiman A, Feštšenko D, Vilu R. Nutritional requirements and media development for Lactococcus lactis IL1403. Appl Microbiol Biotechnol. 2014;98:5871-81. doi:10.1007/s00253-014-5641-7.

Broadbent JR, Larsen RL, Deibel V, Steele JL. Physiological and transcriptional response of Lactobacillus casei ATCC334 to acid stress. J Bacteriol. 2010;192(9):2445-58. doi:10.1128/JB.01618-09.

Cocaign-Bousquet M, Garriques C, Novak L, Lindley ND, Loublere P. Rational development of a simple synthetic medium for the sustained growth of Lactococcus lactis. J Appl Microbiol. 1995;79(1):108-16. doi:10.1111/j.1365-2672.1995.tb03131.x.

Cohen R, Persky L, Hadar Y. Biotechnological applications and potential of wood-degrading mushrooms of the genus Pleurotus. Appl Microbiol Biotechnol. 2002;58(5):582-94. doi:10.1007/s00253-002-0930-y.

Daniel C, Roussel Y, Kleerebezem M, Pot B. Recombinant lactic acid bacteria as mucosal biotherapeutic agents. Trends Biotechnol. 2011;29(10):499-508. doi:10.1016/j.tibtech.2011.05.002.
De Man JC, Rogosa M, Sharpe ME. A medium for the cultivation of lactobacilli. J Appl Microbiol. 1960;23:130-5. doi:10.1111/j.1365-2672.1960.tb00188.x.

D'Souza R, Pandeya DR, Hong S. Review: Lactococcus lacits: an efficient gram positive cell factory for the production and secretion of recombinant protein. Biomed Res. 2012;23(1):1-7.

Gorbach SL. The discovery of Lactobacillus GG. Nutr Today. 1996;31:25-45. doi:10.1097/00017285-199611001-00002.

Hansson L, Häggström MH. Effects of growth conditions on the activities of superoxide dismutase and NADH-oxidase/NADH-peroxidase in Streptococcus lactis. Curr Microbiol. 1984;10:345-51. doi:10.1007/BF01626563.

Jensen PR, Hammer K. Minimal requirements for exponential growth of Lactococcus lactis. Appl Environ Microbiol. 1993;59:4363-6.

Kelly WJ, Ward LJH, Leahy SC. Chromosomal diversity in Lactococcus lactis and the origin of dairy starter cultures. Genome Bio Evol. 2010;2:729-44. doi:10.1093/gbe/evq056.

LeBlanc JG, Laiño JE, Juarez del Valle M, Vannini V, van Sinderen D, Taranto MP, Font de Valdez G, Savoy de Giori G, Sesma F. B-group vitamin production by lactic acid bacteria-current knowledge and potential applications. J Appl Microbiol. 2011;111:1297-309. doi:10.1111/j.1365-2672.2011.05157.x

Li S, Shah NP. Effects of Pleurotus eryngii polysaccharides on bacterial growth, texture properties, proteolytic capacity, and angiotensin-converting enzyme-inhibitory activities of fermented milk. J Dairy Sci. 2015;98(5):2949-61. doi:10.3168/jds.2014-9116.

Loubiere P, Cocaign-Bousquet M, Matos J, Goma G, Lindley ND. Influence of end-products inhibition and nutrient limitations on the growth of Lactococcus lactis subsp. lactis. J Appl Microbiol. 1997;82:95-100. doi:10.1111/j.1365-2672.1997.tb03302.x.

Manzi P, Gambelli L, Marconi S, Vivanti V, Pizzoferrato L. Nutrients in edible mushrooms - an inter-species comparative study. Food Chem. 1999;65:477-82. doi:10.1016/S0308-8146(98)00212-X.

Olsen HC, Qutub AH. Influence of trace elements on the acid productions by lactic cultures. Cult Dairy Prod. 1970;5:12-7.

Price CE, Zeyniyev A, Kuipers OP, Kok J. From meadows to milk to mucosa-adaptation of Streptococcus and Lactococcus species to their nutritional environments. FEMS Microbiol Rev. 2012;36:949-71. doi:10.1111/j.1574-6976.2011.00323.x.

Rodriguez N, Torrado A, Corrado A, Cortés S, Dominguez JM. Use of waste materials for Lactoccus lactis development. J Sci Food Agric. 2010;90(10):1726-34. doi:10.1002/jsfa.4008.

Stajić M, Vukojević J, Duletić-Laušević S. Biology of Pleurotus eryngii and role in biotechnological processes: a review. Crit Rev Biotechnol. 2009;29(1):5566. doi:10.1080/07388550802688821.

Terzaghi BE, Sandine WE. Improved medium for lactic streptococci and their bacteriophages. Appl Microbiol. 1975;29:807-13.

van Niel EWJ, Hahn-Hägerdal B. Nutrient requirements of lactococci in defined growth media. Appl Microbiol Biotechnol. 1999;52:617-27. doi:10.1007/ s002530051569.

Wang PC, Lin YD, Liaw LL, Chern RS, Chen SC. Lactococcus lactis subspecies lactis also causes white muscle disease in farmed giant freshwater prawns Macrobracbium rosenbergii. Dis Aquat Organ. 2008;79:9-17. doi:10.3354/ dao01868.

Wyszyńska A, Kobierecka P, Bardowski J, Jagusztyn-Krynicka EK. Lactic acid bacteria-20 years exploring their potential as live vectors for mucosal vaccination. Appl Microbiol Biotechnol. 2015;99:2967-77. doi:10.1007/ s00253-015-6498-0.

Zhao Y, Li P, Hu H, Wang Y, Sun Y, Huang K. Postharvest decay of the cultivated mushroom Pleurotus eryngii caused by Lactococcus lactis subsp. lactis. J Plant Pathol. 2013:95(2):247-53. doi:10.4454/JPP.V9512.019. 